Revista Thema

\begin{tabular}{l|l|l} 
V.20 Especial 2021 & Es
\end{tabular}

p.287-302

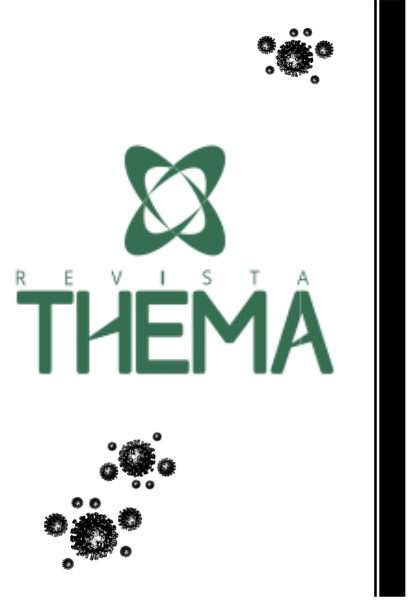

DOI: http://dx.doi.org/10.15536/thema.V20.Especial.2021.287-302.1848

ISSN: 2177-2894 (online)
CIÊNCIAS DA SAÚDE

\section{Experiência vivida de jogadoras de futebol em tempos de COVID-19}

\section{Experience of woman soccer players in COVID-19 times}

Annie Rangel Kopanakis ${ }^{1}$, Débora Ortolan Fernandes de Oliveira ${ }^{2}$, Tania Maria José Aiello-Vaisberg ${ }^{3}$

\title{
RESUMO
}

O presente trabalho tem como objetivo estudar a experiência vivida por jovens atletas do futebol feminino profissionalizante durante a pandemia de COVID-19, justificando-se pelo interesse em compreender e cuidar dos efeitos psicológicos do isolamento social. Articula-se, metodologicamente, como um estudo de caso, inserido no rol de pesquisas qualitativas com uso do método psicanalítico, na perspectiva da psicologia psicanalítica concreta. Utiliza, como material de pesquisa, comunicações emocionais de nove atletas, feitas durante atendimentos psicológicos grupais realizados remotamente. A análise do material leva a resultados interpretativos que se apresentam sob forma de dois campos de sentido afetivo-emocional, que refletem uma condição de sofrimento emocional socialmente determinado: "Ecos da casa grande e senzala" e "Carreiras contaminadas". Esse quadro geral enseja uma discussão sobre os modos pelos quais trajetórias de vida, concebidas como caminho de escape da pobreza, podem ser traumaticamente abaladas quando se percebe que fatos totalmente fora da possibilidade de controle individual podem colocar projetos pessoais em risco.

Palavras-chave: Futebol feminino; pandemia de coronavírus; psicoterapia online; método psicanalítico.

\section{ABSTRACT}

The present paper aims to study the experience of youth female soccer players during the COVID-19 pandemic, justified by the interest in understanding and taking care of the psychological effects of social isolation. It is articulated, methodologically, as a case study, inserted in the list of qualitative research using the psychoanalytic method, in the perspective of concrete psychoanalytic psychology. It uses, as research material, emotional communications from nine athletes, made during online psychotherapy groups. The analysis of the material leads to interpretative results that are presented in the form of two fields of affective-emotional, which reflect a condition of socially determined emotional suffering:

\footnotetext{
${ }_{1}$ Doutoranda em Psicologia, Pontifícia Universidade Católica - PUC, Campinas/SP - Brasil. E-mail: annie_rk@hotmail.com

${ }^{2}$ Idem. E-mail: debora.ortolan@yahoo.com.br

${ }^{3}$ Pontifícia Universidade Católica - PUC, Campinas/SP - Brasil. E-mail: aiello.vaisberg@gmail.com
} 
"Echoes of the big house and slave quarters" and "Contaminated careers". This general picture gives rise to a discussion about the ways in which life trajectories, conceived as a way out of poverty, can be traumatically affected when it is realized that facts totally beyond the possibility of individual control can put personal projects at risk.

Keywords: Women's soccer; coronavirus pandemic; online psychotherapy; psychoanalytic method.

\section{INTRODUÇÃO}

A eclosão da pandemia causada pela COVID-19 levou a Organização Mundial de Saúde a recomendar medidas de isolamento social como estratégia de controle do contágio. Consequentemente, muitas atividades coletivas, que implicam interação próxima entre pessoas, foram temporariamente suspensas. Centros comerciais, escolas, restaurantes, academias de ginástica, serviços estéticos e muitas outras, nos quais se dão atividades classificadas como não-essenciais, tiveram suas portas fechadas. Empresas e escritórios se esvaziaram, enquanto seus funcionários passaram a realizar suas tarefas comunicando-se via internet em sistema de home-office. Enfim, a rotina da maior parte das pessoas sofreu grandes mudanças, numa atmosfera de certo temor e ansiedade, uma vez que a doença em pauta, por sua alta taxa de transmissibilidade, gera grande número de óbitos, mesmo que não apresente elevado grau de letalidade. No caso do Brasil, a pandemia veio a agravar problemas estruturais, que atingem de modo marcante um grande contingente populacional, situado nas camadas mais pobres da população. Problemas ligados a questões de saúde, educação, moradia, transporte e saneamento, que normalmente penalizam as classes trabalhadoras, resultaram em situações concretas que revelam, com grande clareza, que a pandemia atinge diferentemente as classes médias e aqueles que vivem em condições marcadas por carências fundamentais. (BARRETO et al., 2020).

No setor esportivo, jogos e campeonatos foram cancelados, para reduzir as possibilidades de contágio e evitar o convívio dos torcedores nos estádios. Os próprios treinamentos dos atletas sofreram interrupção, na medida em que implicam, nas modalidades coletivas, convivência grupal próxima. Os clubes, que oferecem capacitação esportiva para categorias de formação, viram-se numa condição que impunha interrupção dos treinos e desocupação de alojamentos coletivos, com consequente envio dos jovens atletas para suas casas. Profissionais encarregados do trabalho direto com os atletas, como técnicos, preparadores físicos e demais profissionais envolvidos com o futebol, viram sua rotina de trabalho bruscamente modificada, em seu cotidiano, enquanto os psicólogos, assistentes sociais e pedagogos passaram a ser mais procurados, bem como a perceber um aumento de manifestações de sofrimento emocional, no sentido de apresentação de sintomas depressivos e ansiosos, que apontam para a importância do cuidado da saúde mental destes jovens. (FILGUEIRAS; STULTS-KOLEHMAINEN, 2020). Na mesma linha, também as gestões das agremiações esportivas, conscientes de que o isolamento social dos atletas, em seus domicílios familiares, representa, num número significativo de casos, 
um retorno a condições de vulnerabilidade social, vieram a considerar atentamente esse problema. (CBF SOCIAL, 2020a; 2020b).

Por outro lado, psicólogos da área esportiva, entre os quais nos incluímos, levando em conta iniciativas, aprovadas pelos órgãos oficiais de orientação e fiscalização da prática da profissão, de realização de atendimentos individuais e grupais por internet (CFP, 2018), inaugurando uma modalidade de atendimento pouco usada, até então, no contexto esportivo, já que os atletas seguem uma rotina de treinos diários e habitualmente residem em alojamentos institucionais, já que são frequentemente provenientes de outras cidades e estados.

De modo geral, tem sido bastante expressiva a receptividade dos atletas, das várias categorias, que envolvem diferenças de idade e gênero, à oferta de atenção psicológica à distância. Tal fato mostra que se dispõem a utilizá-la não presencialmente, seja porque já têm a experiência de receber atenção psicológica no clube, seja porque são capazes de perceber que a pandemia, e as alterações das atividades que impõem, tendem a gerar mal-estar psicológico mais ou menos pronunciado. Um dos grupos, que mostrou clara abertura a aderir às propostas de ser atendido por internet, durante o período de isolamento social, é aquele constituído por atletas de sexo feminino, que focalizamos na presente pesquisa.

A inclusão de mulheres, em processo de formação profissional futebolística, é um acontecimento relativamente recente, de modo que poucos clubes mantêm categorias de base de futebol feminino, o que se explica pelo fato dessa modalidade esportiva ter conhecido uma história complexa, que inclui discriminação e exclusão de mulheres, que provavelmente ainda repercute nos dias de hoje. (MENDONÇA, 2019). De fato, é importante lembrar que o futebol feminino foi proibido por lei, em nosso país, entre os anos de 1941 e 1979, conforme Pisani (2018) e Silva (2015), o que demonstra a interferência de questões de gênero que ainda não foram completamente superadas. Portanto, se os jogadores enfrentam muitas dificuldades de carreira, maiores são aquelas que com as quais se defrontam as jogadoras.

Quando escutamos as jogadoras, em enquadres psicológicos, podemos realizar um duplo trabalho. De um lado, temos oportunidade de favorecer processos de amadurecimento que incluem a tarefa existencial de lidar com o ser mulher numa sociedade predominantemente conservadora e machista. Desse modo, atendemos às preocupações, nossas e dos gestores dos clubes, com sua saúde mental. Por outro lado, mesmo operando a partir de estudos de casos, que não permitem generalização imediata de resultados, contribuímos também para a produção de conhecimento compreensivo, indispensável no que diz respeito ao cuidado psicológico do atleta como pessoa, como no que diz respeito aos modos pelos quais a psicologia pode contribuir com processos de formação e capacitação esportiva. Quando a escuta psicológica se faz em situações de crise (BLEGER, 1966), como a presente, temos oportunidade de aprender mais tanto sobre a experiência vivida pelos atletas nos campos vinculares nos quais convivem, e nos contextos macrossociais em que se inserem. 
Para atender às exigências da pesquisa qualitativa que praticamos, usando o método psicanalítico na perspectiva da psicologia psicanalítica concreta nesse estudo de caso, realizamos um recorte em nosso trabalho, optando por focalizar, nesse momento, a experiência vivida por nove atletas do futebol de base feminino, com idades entre 15 e 18 anos, de um clube da região sudeste do país.

\section{DESENVOLVIMENTO}

O presente estudo, que tem como objetivo investigar a experiência emocional de jovens jogadoras de futebol feminino de base, durante o afastamento social vinculado à eclosão da pandemia do COVID-19, pertence a um rol de pesquisas qualitativas que se caracterizam por utilizar o método psicanalítico na perspectiva da psicologia psicanalítica concreta. (BLEGER, 2007). Portanto, faz parte de uma iniciativa que visa a produção de conhecimentos compreensivos sobre sentidos afetivo-emocionais, eventualmente não conscientes, de fenômenos humanos, que emergem a partir de campos vinculares que se inserem em contextos macrossociais.

A perspectiva teórico-metodológica, na qual nos fundamentamos foi criada por Politzer (2004) e desenvolvida por Bleger (1958), a partir de uma análise crítica que identificou duas vertentes incompatíveis nos textos freudianos: uma, de caráter objetivante e fisicalista, conhecida como metapsicologia, que pensa o psiquismo como aparelho óptico e outra, vincular, clínica e dramática, que se firma como ciência do acontecer intersubjetivo, voltada ao estudo dos sentidos afetivo-emocionais dos atos humanos. A psicologia psicanalítica concreta consiste numa elaboração pós-freudiana que se caracteriza como contribuição vinculada ao paradigma relacional, descrito por Greenberg e Mitchel (1994). Difere de outras propostas relacionais pelo fato de atribuir grande relevância aos contextos macrossociais em que se inserem os campos vinculares, considerando que condições sociais estruturais, como o classismo, o machismo e o racismo, afetam profundamente o bem-estar psicológico. Assim, destoando de uma tendência psicanalítica muito comum, de limitar o coletivo ao registro familiar, não deixa de levar em conta dimensões sociais a partir das quais o familiar e o individual são vividos e pensados. Tal posicionamento se torna extremamente valioso quando nos interessamos pelos modos como determinações sociais geram sofrimentos emocionais.

Por outro lado, é importante salientar que a psicologia psicanalítica concreta se oferece, antes de mais nada, como abordagem que não privilegia teorias prontas e acabadas, mas sim o processo investigativo que pode favorecer a emergência de novos conhecimentos, de caráter compreensivo, local e comprometido com transformações do viver. A valorização do caráter local do conhecimento produzido indica a consciência, dos pesquisadores, de que esse modo de investigar não permite operações imediatas de generalizações, mas, por outro lado, torna o participante um beneficiário imediato da compreensão alcançada, segundo um esquema que caracteriza a investigação de caráter interventivo. 


\section{Edição Especial COVID-19}

Os conceitos fundamentais da psicologia psicanalítica concreta, forjados a partir de uma leitura concreta das contribuições freudianas não metapsicológicas, bem como de práticas de atuação em pesquisas clínicas interventivas, são conduta, campo e experiência vivida. (BLEGER, 2007).

O conceito de conduta se refere à ideia de que todos os atos e manifestações humanas que, no entender de Bleger (2007) são o objeto de estudo de todas as chamadas ciências humanas, estão sempre atravessados por inúmeros sentidos. Cada ciência abarcará certo conjunto de qualidades e características desses atos humanos, relacionados a diferentes tipos de sentido: sociais, econômicos, culturais, históricos, geopolíticos e religiosos, entre outros. A psicologia se singulariza, nesse conjunto, por voltar-se à pesquisa de sentidos afetivo-emocionais que podem ser, eventualmente não conscientes. Assim, desde a perspectiva da psicologia, os atos humanos serão recortados como emergentes de campos vinculares, inter-relacionais, não se reduzindo à exteriorização do psiquismo individual. Por outro lado, os campos vinculares, também denominados campos de sentido afetivo-emocional, estarão sempre inseridos em contextos macrossociais.

Os campos de sentido afetivo-emocionais correspondem à visão do inconsciente característica da psicologia psicanalítica concreta. Não se trata de um inconsciente pensado como instância endopsíquica, mas de uma dimensão sensível, intuitiva e préreflexiva do viver, que sempre ultrapassa o que, a cada instante, pode ser abarcado pelo campo da consciência. (BLEGER, 2007). Como inconscientes intersubjetivos, os campos, segundo os quais se organizam os imaginários coletivos, podem ser pensados como ambientes produzidos e habitados por pessoalidades individuais e coletivas. Correspondem, portanto, aos resultados a que chegamos quando realizamos pesquisa qualitativa com método psicanalítico na perspectiva da psicologia psicanalítica concreta.

Outro conceito fundamental em nossas pesquisas é aquele de experiência vivida cuja abordagem psicanalítica deveria ser celebrada, conforme Politzer (2004), por corresponder ao surgimento de uma ciência na "primeira pessoa", voltada à compreensão da subjetividade.

A experiência vivida corresponde ao modo humano de ser e existir no mundo, abrangendo o pensar, o sentir e o agir, que são indissociáveis mesmo quando contraditórios. Seu estudo científico, configurando uma ciência da "primeira pessoa", surgiu com a psicanálise que, desse modo, tornou-se, no entender de Politzer (2004) um saber revolucionário que cabia celebrar. Incluindo, mas não se limitando ao que é conscientemente pensado, as experiências são vividas como modos de habitar os campos de sentido afetivo-emocional, cuja compreensão confere profundidade aos estudos psicológicos, sobretudo porque incluem questões do inconsciente intersubjetivo, que estão presentes na dramática da vida humana. (GALLO-BELUZZO; CORBERT; AIELLO-VAISBERG, 2013). Assim, podemos afirmar que a pessoa humana equivale à experiência vivida por cada um, na condição de habitante de campos vinculares. A partir do reconhecimento, enfatizado por Bleger (2007) de que o ser humano se define como fundamentalmente social, suas experiências ocorrem em 
mundos humanos, que se constituem sempre como realidades imaginativamente engendradas.

Desta forma, articulando os conceitos de conduta, campos de sentido afetivoemocional e experiência vivida, tal como estabelecidos na perspectiva da psicologia psicanalítica concreta, tornamo-nos aptos a buscar a compreensão de comunicações relativas à experiência vivida por nove jogadoras de futebol feminino de base, durante a vigência do isolamento social domiciliar adotado ao decorrer a pandemia de COVID-19.

\subsection{PROCEDIMENTOS INVESTIGATIVOS DE PESQUISA}

Com objetivo de produzir conhecimento compreensivo acerca de experiência vivida de nove jogadoras de futebol feminino de base, que tiveram interrompidas suas rotinas de treinamento diário no clube de futebol, para serem enviadas aos domicílios de suas famílias, em função do isolamento social acionado contra o contágio ao COVID-19, operacionalizamos o método psicanalítico em termos de três procedimentos investigativos: de produção, de registro e de interpretação do material de pesquisa.

O procedimento investigativo de produção do material de pesquisa deu-se através da realização de atendimentos clínicos grupais, realizados em plataformas online, psicanaliticamente orientados, que se fundamentam na adoção de enquadres clínicos diferenciados. (MENCARELLI; BAPTISTA; AIELLO-VAISBERG, 2017). Tais sessões ocorreram em ambiente virtual e delas participaram nove atletas. Torna-se importante mencionar que as atletas participantes da presente pesquisa são jovens com idades variando entre 15 e 18 anos, de classes sociais baixas e estudantes do ensino médio. As participantes são fisicamente saudáveis e não apresentam problemas de rebaixamento intelectual nem diagnósticos psiquiátricos.

O procedimento investigativo de registro do material de pesquisa consistiu na elaboração das narrativas transferenciais. (AIELLO-VAISBERG; VITALLI; GIORGIO; AMBROSIO, 2003). Essa forma de registro demanda o cultivo da atenção flutuante e da associação livre de ideias, pilares do método psicanalítico, o que permite que pesquisadoras/ psicanalistas focalizem tanto o ocorrido, em termos das interações, como os impactos afetivo-emocionais que vivenciaram no encontro. Apresentam, como importante vantagem, que recomenda seu uso, o fato de permitir que a sessão transcorra sem interferências que comprometeriam 0 campo transferencial. (BLEGER, 1993).

Quanto ao procedimento investigativo de interpretação do material de pesquisa, lemos e relemos, repetidas vezes, as narrativas transferenciais, procurando reconhecer as impressões que nos suscitam (AIELLO-VAISBERG; MACHADO, 2007), com vistas a seguir as diretrizes interpretativas, forjadas por Herrmann (1979): “deixar que surja", "tomar em consideração" e "completar a configuração de sentidos emergentes". A partir daí, chegamos à proposição dos campos de sentido afetivoemocionais, que correspondem ao inconsciente intersubjetivo com o qual trabalha a psicologia psicanalítica concreta. (BLEGER,2007). 
Finalmente, suspendemos o uso do método psicanalítico, para discutir os resultados interpretativos sob forma de estabelecimento de interlocuções reflexivas. Nessa ocasião realizamos um trabalho de teorização reflexiva e dialógica, buscando ampliar nossa compreensão por meio de interlocuções com autores que se debruçaram sobre questões para as quais os campos de sentido afetivo-emocional, que produzimos interpretativamente, apontam. Não nos propusemos a realizar generalizações, dado o fato de estarmos usando uma metodologia de estudo de caso, conforme o habitual nos estudos que usaram referenciais psicanalíticos como a psicologia psicanalítica concreta, que vem construindo conhecimento sobre o humano por meio do acúmulo de pesquisas que produzem conhecimentos locais.

\subsection{RESULTADOS INTERPRETATIVOS: CAMPOS DE SENTIDO AFETIVO- EMOCIONAL}

A consideração psicanalítica do material permitiu que criássemos/encontrássemos dois campos de sentido afetivo-emocional: "Ecos da casa grande e senzala" e "Carreiras contaminadas". Esses dois campos correspondem aos nossos resultados interpretativos, e equivalem, na perspectiva da psicologia psicanalítica concreta, a inconscientes intersubjetivamente produzidos, que não são pensados como endopsíquicos, mas como verdadeiros ambientes psicológico-vivenciais habitados por pessoalidades individuais e coletivas.

O campo de sentido afetivo-emocional "Ecos da casa grande e senzala" define-se como aquele que circula ao redor da crença de que as diferenças socioeconômicas determinam o modo como o isolamento é vivido. Esse campo se expressa, por exemplo, pelo fato das atletas participarem das sessões desde suas próprias casas, o que torna visíveis aspectos materiais dos domicílios, ao mostrar ambientes, equipamentos disponíveis e local de moradia, eventualmente bastante distanciado dos grandes centros. Outra maneira, pela qual a pobreza maior, de algumas jogadoras, fez-se aparente, consistiu no fato de permanecerem no alojamento por falta de recursos próprios para custear seu deslocamento até as moradias de suas famílias. Esse grupo era constituído por atletas negras, que expressaram sofrimento emocional aparentemente mais intenso, descrevendo experiências de tédio, insônia, compulsão por comer, choro, preocupações e desamparo, que se atenuaram quando o clube se encarregou de fornecer os meios para a realização das viagens de retorno às casas.

Como exemplos desse campo, citamos os seguintes trechos das narrativas transferenciais, feitas pelas pesquisadoras, após cada intervenção, com vistas a registrar o acontecer clínico:

"Diferente das outras meninas, ela não estava dentro de um quarto individual, com portas fechadas. Ela transitava pela casa em busca de um espaço, uma melhora da conexão, mas logo chegava alguém. Essa jovem, pobre, claramente não tem as mesmas condições de vida que as outras colegas." 
"De certa forma, muitas abrandaram seus relatos, dizendo que estão em casa, passando tempo com a família, que dormem bem, jogam baralho... ou seja, nada próximo da bagunça emocional que enfrentam as colegas que não vivem a mesma situação."

"As meninas que não voltaram ainda para suas casas têm algo em comum: são de muito longe da cidade do clube. Assim, o retorno para a casa para passar a quarentena, como a maioria das meninas pode fazer, torna-se algo complicado. A viagem de ônibus é longa, o medo de contaminar a família está presente."

O campo "Carreiras contaminadas" organiza-se ao redor da crença de que a interrupção dos treinos, durante os quais as realmente esforçadas se desenvolvem como atletas, pode comprometer sua profissionalização. Esse campo se expressa, nas comunicações das jovens, por meio de verbalizações que versa sobre preocupações e temores relativos à possibilidade de que suas aspirações, pelas quais se empenham, não se concretizem, no futuro, em função de um acontecer que não depende absolutamente de seus próprios esforços.

Como exemplos desse campo, citamos os seguintes trechos das narrativas transferenciais:

"Disse que imaginava a roupa, o chapéu de formatura, mas que temia que isso não fosse mais possível daqui pra frente e que isso decepcionaria a ela e a sua família que esperavam muito por esse momento especial."

"As incertezas rondam o encontro. Falam da preocupação em se manter fisicamente em forma por conta dos campeonatos deste ano e da possibilidade de terem as carreiras prejudicadas pela pandemia e a angústia de não ter previsões sobre a continuidade deste projeto de vida delas!"

"Elas trouxeram suas angustias de que os treinos não voltem e falaram sobre a saudades dos jogos e a preocupação da pandemia atrapalhar suas carreiras."

\subsection{INTERLOCUÇÕES REFLEXIVAS}

A experiência vivida por atletas de futebol feminino de base durante a pandemia desvela sofrimentos socialmente determinados (RENAULT, 2010), que atravessam e desnudam duas problemáticas estreitamente relacionadas: a desigualdade social e meritocracia. A desigualdade social é uma condição objetiva, sobre a qual existe literatura específica copiosa (SOUZA, 2003; 2009), que é compreendida segundo o posicionamento ideológico, nem sempre consciente. A meritocracia é fenômeno concreto enquanto crença imaginativa de que o sucesso depende exclusivamente de dedicação e esforço pessoal, não sendo afetado pelas condições concretas de vida. (BLEGER, 2007). Esse segundo problema está no cerne das aflições vivenciadas no campo "Carreiras contaminadas". 
Na medida em que a pandemia torna mais visível a extrema desigualdade social brasileira, o campo "Ecos da casa grande e senzala" traz à tona os dramas vividos por grande parte dos jovens brasileiros e brasileiras que se encontram em situações socioeconomicamente desfavorecidas, demonstrando as consequências de uma sociedade marcadamente desigual. Em tempos normais, as participantes dessa pesquisa, bem como todos os seus colegas, encontram no clube condições que minimizam a visibilidade das diferenças socioeconômicas, pois compartilham ambientes comuns de trabalho e alojamentos coletivos, além de vestirem uniformes. Essa questão é bastante significativa quando lembramos que, embora a grande maioria provenha de camadas menos favorecidas da população, os graus de carência, existentes entre as atletas, podem ser muito diversos. Durante a pandemia, por outro lado, os ambientes domésticos, o tipo de equipamento disponível para conexão virtual, o local de moradia, eventualmente muitíssimo afastado dos grandes centros, torna as diferenças muito perceptíveis, de modo que diversidades, anteriormente menos notadas, acabam por se destacar.

Parece-nos conveniente lembrar aqui que prevalece hegemonicamente, no mundo capitalista, uma visão de meritocracia segundo a qual a pobreza seria produzida pelo próprio pobre, que só permaneceria nessa condição por não ter se esforçado o bastante para ascender socialmente. (AIELLO-FERNANDES, 2013). Tal imaginário é constantemente fortalecido, o que contribui para favorecer o ocultamento de manobras de dominação e exploração das classes subalternas. Sendo assim, o mero fato de pertencer a tais classes é algo que já se faz acompanhar de sofrimento social, provocando sentimentos de desamparo e humilhação. (RENAULT, 2010). Assim, as jogadoras, que se empenham na profissionalização futebolística, motivadas, em grande medida, pela perspectiva de ascensão social, viram-se subitamente, em função do isolamento social, em contato muito próximo com as carências de suas famílias e das famílias de suas colegas.

Ao entrarmos em contato com a experiência vivida por jogadoras em formação, em tempos de pandemia, no Brasil, assinalamos que se fazem necessárias reflexões acerca da realidade nacional, com vistas à compreensão apurada do fenômeno da desigualdade, bem como da complexa composição social, na qual muitas instituições reforçam as disparidades sociais vigentes. (SOUZA, 2003; 2009). Segundo Renault (2010), a partir do reconhecimento da injustiça contemporânea, como provocadora de situações de desamparo e humilhação, as sociedades devem se reorganizar radicalmente se optam por valores humanistas.

De acordo com Jessé Souza (2003), ocorre, no Brasil, um processo de naturalização da desigualdade, que muitas vezes não se torna consciente naqueles que são suas vítimas. O capitalismo periférico, somado à impessoalidade com que as relações humanas se estabelecem, alimenta esse processo de invisibilidade do problema. Ao criar o conceito de subcidadania, que implica uma hierarquia do valor atribuído às pessoas, o autor expõe que as raízes da desigualdade social no Brasil são profundas e ultrapassam a condição econômica, visto que também se fundamenta em construções 
simbólicas que indicam quem merece e quem não merece ter sua dignidade humana respeitada.

Como visto, a naturalização da desigualdade social atinge tal ponto, na vida cotidiana, que permanece pouco acessível à percepção. Essa naturalização se associa profundamente à ideia de meritocracia, que vai tornar banal a equivalência entre pobreza e incompetência para progredir. Percebemos que as trajetórias de vida, vistas a partir dessa compreensão de que a ascensão social depende do esforço individual, blindam a possibilidade de enxergar a pobreza como fenômeno socialmente produzido, na contemporaneidade, pelo sistema capitalista. Ao vivermos sob as égides de um ideal de justiça que se apoia na meritocracia, de modo a desconsiderar a produção social de obstáculos ao acesso a uma vida na qual as necessidades humanas são atendidas, condenamos parte da população a um sofrimento social e emocional significativo e injusto. (SOUZA, 2003; 2006).

Reconhecemos, no campo de sentido afetivo-emocional "Ecos da casa grande e senzala", o sentimento de humilhação que, sob vigência da meritocracia, indicaria a incompetência das pessoas e das famílias, ocultando a desigualdade injusta. Além disso, as disparidades sociais, que determinam acessos distintos ao consumo, geram, na parcela mais desfavorecida, sentimentos de humilhação e vergonha por ver desvelada sua suposta incapacidade. Assim essa organização produz reconhecimento e oportunidades para poucos e humilhação e problemas de autoestima para muitos, denotando que a desigualdade e a pobreza são fenômenos que estão profundamente imbricados na dimensão afetivo e emocional do ser humano.

As saídas da população, que vive em condições sem acesso a direitos fundamentais, como educação, saúde, moradia, saneamento, transporte, informação, lazer e cultura de qualidade, muitas vezes é encontrada por meio de profissões que dispõem do corpo como ferramenta de trabalho. (SOUZA, 2003). Essa compreensão faz com que o futebol figure enquanto possibilidade de profissão compreendida, por muitos, quase que exclusivamente como talento do corpo.

Em consonância com essa reflexão, percebemos, no campo "Carreiras contaminadas", que a pandemia de COVID-19 está sendo vivenciada pelas atletas como uma ameaça à realização de seus sonhos, de seguir uma carreira no futebol, que dependeria, na perspectiva da meritocracia, basicamente de seus esforços e de sua dedicação aos treinos. Assim, sendo pessoas que vivem numa sociedade em que a meritocracia é uma crença dominante, tornam-se muito afetadas ao perceberem que os rumos de suas vidas podem ser profundamente alterados por algo, como a disseminação de um vírus, fora de seu controle, que as impede de treinar - porque o treinamento é a via da conquista da capacidade de se tornar uma pessoa vencedora. O mundo do clube esportivo, no qual as diferenças parecem depender de dedicação e talento pessoal, fica, desse modo, invadido pelo mundo social que, num país como o nosso, realiza-se sob a forma de exploração econômica radical da população e de batalhas cotidianas pela sobrevivência cujos resultados podem ser muito parcos ou mais ou menos satisfatórios, conforme uma multiplicidade de fatores alheios às ações individuais. 
Consequentemente, o futebol como meio da busca por sucesso pessoal, resultados e vitória, alcançados a partir de um esforço substancial, favorece um imaginário conforme o qual o atleta bem-sucedido seria um herói. (RODRIGUES, 2016; RÚBIO, 2001). Assim sendo, ocorre uma busca da superação a qualquer custo, o que pode se tornar mais evidente e aflitivo em tempos de pandemia. A crença na possibilidade de se tornar uma atleta heroína, que alcançaria sucesso fundado na dedicação pessoal, desencadeia muitos sofrimentos emocionais por desconsiderar como as condições concretas de vida dos jovens aspirantes a jogadores e jogadoras profissionais afetam diretamente seu percurso na carreira. Aquele que perde seria, portanto, o único responsável por sua derrota. Entretanto, no quadro da pandemia, essa crença, em si mesmo complexa, pois de um lado estimula dedicação, mas de outro engana, ao ocultar os determinantes sociais da desigualdade e da pobreza, passa a exercer efeito traumático, ao mostrar como realidades que antes pareciam tão estáveis, como os calendários das competições e os estádios lotados, podem ser suspensos de um dia para outro, sem previsão de volta à normalidade.

Com auxílio de Camps, Barcelos e Aiello-Vaisberg (2014), que estudaram imaginários de adolescentes brasileiros de classe média, constatamos que a compreensão de que uma vida respeitável seria aquela que ocorre em boas condições financeiras, ou seja, que oferece possibilidades de consumo e realização pessoal, parece se constituir como uma visão bastante comum na sociedade em que vivemos. Uma boa condição de vida seria conquistada por meio esforços individuais que independeriam das condições concretas de vida. Os achados dessa pesquisa corroboram com o que encontramos na presente investigação que, em consonância, também revela, por meio do campo "Carreiras contaminadas", a crença de jovens atletas de que o sucesso pessoal depende exclusivamente de seu próprio esforço. Assim, convergem os resultados do trabalho dessas duas pesquisas, realizadas, em nosso país, com participantes da mesma faixa etária, mas de diferentes condições socioeconômicas. Por esta via, ambos os grupos enxergam-se como absolutamente responsáveis pelo sucesso que podem vir a alcançar a partir dos próprios esforços, o que traz, como corolário, que todo fracasso deve ser atribuído à própria pessoa. Tal equacionamento do viver facilita a manipulação cruel das necessidades emocionais de reconhecimento e valor pessoal, pelo ocultamento de que carências estão intimamente relacionadas com a realidade sociopolítica.

Castellano (2005) tece uma importante crítica acerca da idealização do sucesso como resultado do esforço pessoal. Ao estabelecer um resgate histórico, usando livros de autoajuda como material de pesquisa, a autora mostra como a incorporação da noção de sucesso, concomitante à adoção do modelo de desenvolvimento capitalista, contribui para a construção das subjetividades contemporâneas ligadas à ideia de que há uma capacidade individual de transformar a própria trajetória, a despeito do cenário social em que o sujeito está inserido e, ainda, dos antecedentes que marcaram sua vida. Essa ideologia meritocrática favorece a instauração de verdadeiras batalhas pessoais pelo alcance de melhor desempenho. É nesse contexto que o esporte deve ser visto atualmente, como atividade fortemente associada ao 
culto da performance e da competitividade, extremamente calcada na divisão da sociedade entre as figuras do vencedor e do fracassado, sempre tidos como responsáveis únicos e diretos por suas próprias trajetórias.

Ainda de acordo com Castellano (2005), a priorização de uma lógica, que menospreza o fracasso, confere uma depreciação ao sofrimento humano, que passa a ser considerado como fraqueza. Tal lógica acaba debilitando o espaço do esporte, que poderia ser convidativo a experiências de amadurecimento emocional, na medida em que oferece oportunidade de viver uma grande variedade de interações e situações. Afinal, a pessoa que imagina que o viver deve ser uma sucessão de ganhos e sucessos não estará preparada para sentir-se vivo, real e capaz de gestualidade autêntica em todos os momentos de sua própria vida. (WINNICOTT, 1988).

Torna-se importante mencionar que, em nossa experiência profissional, ao trabalhar com atletas das mais variadas idades, identificamos um ambiente esportivo extremamente permeado por essa valoração do sucesso supostamente conquistado por quem tem "espírito vencedor" ou é "mentalmente forte", como se a saúde psíquica humana fosse conquistada com um treinamento, uma espécie de musculação da mente e do cérebro, numa compreensão que, ao final, desumaniza e despersonaliza o atleta. Esse mundo é aquele que adentra o jovem que escolhe a carreira futebolística como profissão, geralmente buscando se aproximar de uma atividade que o encanta para toma-la como via de entrada no mundo do trabalho. (MANDEL, 2016; VIEIRA, 2001). A busca pela profissionalização futebolística como meio de superação da pobreza já fora descrita por Rodrigues (2016), Mandel (2016) e Leme (2011). À vista disso, a compreensão de que a atleta teme ter sua carreira interrompida pela pandemia nos coloca diante do seu sofrimento, pois não é descabida a ideia de que a nova ordem possa interferir negativamente em seus projetos de vida. Sobre essa questão é importante que entendamos que embora o futebol seja muitas vezes compreendido como um esporte que confere altos salários aos atletas, essa é uma realidade que se restringe a uma minoria, que se torna ainda mais restrita quando focalizamos a modalidade específica do futebol feminino.

Com vistas a colaborar com o debate crítico sobre as questões emergentes dos campos de sentido afetivo-emocional "Ecos da casa grande e senzala" e "Carreiras contaminadas", percebemos que as desigualdades sociais no Brasil são uma problemática que aponta para a necessidade de esforços das ciências humanas de produzirem estudos que, além de denunciarem esse fenômeno, produzam conhecimentos que contribuam efetivamente para sua resolução. Nesse sentido, consideramos fundamentalmente importante a percepção de que se trata de fenômeno multifacetado que, para além das perspectivas meramente econômicas e meritocráticas, gera efeitos significativos nos campos afetivo-emocionais em que transcorre a vida humana. Sendo assim, compreendemos, com Renault (2010), que aqueles que são atingidos por sofrimentos sociais, podem se manter não conscientes acerca do prejuízo subjetivo que padecem e, no caso do atleta, seguir aderindo sinceramente à crença de que o verdadeiro herói conquista tudo a partir do próprio esforço, independentemente das condições concretas de vida. Entendemos que tal 
crença possa ser utilizada na intenção de motivar dedicação, mas se trata de recurso perigoso do ponto de vista psicológico na medida em que pode acarretar efeitos traumáticos duradouros.

Desta forma, compreendendo o futebol a partir da cultura da meritocracia, percebemos que, neste momento da pandemia, interromper a luta pessoal pelo sucesso gera profundo sofrimento nas atletas que se tornam habitantes do campo "Carreiras contaminadas", uma vez que são pessoas que visam sair das condições de pobreza e desigualdade que, nesse estudo, manifestaram-se sob forma dos "Ecos da casa grande e da senzala".

\section{CONSIDERAÇÕES FINAIS}

Os fenômenos psicológicos e sociais decorrentes da pandemia de COVID-19 estão sendo estudados por diversas áreas do conhecimento. Cabe à psicologia a abordagem da experiência vivida por pessoalidades individuais e coletivas, nesse período, com vistas à produção de conhecimento compreensivo passível de ser usado em processos de cuidado da saúde mental e emocional. Cabe também a ela fornecer subsídios que possam ser usados em debates no âmbito de movimentos sociais. Contudo, é importante ressaltar que essa forma de trabalho contém limitações, motivo pelo qual incentiva a realização de outras investigações usando diferentes referenciais teóricometodológicos.

A condição pandêmica insere-se entre aquelas que devem ser consideradas como sofrimentos sociais, tais como guerras, desastres ecológicos ou condições contínuas de dominação e opressão como aquelas que caracterizam o racismo, o sexismo e o classismo. Assim, o estudo dos efeitos subjetivos da pandemia sobre vários grupos faz parte de um capítulo importantíssimo no estudo do sofrimento.

Em nosso país, os sofrimentos sociais tendem a penalizar mais fortemente aqueles que se encontram em condições de maior desamparo e de maior humilhação social. $\mathrm{O}$ racismo, a discriminação da mulher e da população LGBT+ são problemas indiscutivelmente prioritários em nosso país, mas estão, via de regra, interseccionados com a pobreza e a desigualdade social. A situação de vida das participantes do presente estudo não é exceção, na medida em que a busca de profissionalização no setor futebolístico raramente está divorciada de tentativas de escapar da pobreza e de ascender socialmente.

Os sofrimentos sociais, não sendo mais do que efeitos subjetivos de condições sociais problemáticas, apontam não apenas para a necessidade de desenvolvimento e expansão de uma clínica psicológica social, mas também para a necessidade de debates ético-políticos, no âmbito dos movimentos sociais e da sociedade civil como um todo, sobre o tipo de vida social que almejamos, para a atualidade e para o futuro, na medida em que estivermos verdadeiramente comprometidos, em nosso país, com o cultivo de um humanismo radical e inclusivo. 


\section{REFERÊNCIAS}

AIELLO-VAISBERG, T. M. J.; VITALLI, L. M.; GIORGIO, S.; AMBROSIO, F. Art-thérapie, clinique winnicottienne et troubles neurologiques sévères. Bulletin de Psychologie, Paris, n.56, v.6, p.791-794, 2003.

AIELLO-VAISBERG, T. M. J.; MACHADO, M. C. L. As narrativas transferenciais como apresentação do acontecer clínico: uma proposta metodológica. In: JORNADA DE PESQUISA EM PSICANÁLISE E FENOMENOLOGIA CAMPINAS, 2007, Campinas. Anais... Campinas: Pontifícia Universidade Católica de Campinas, 2007.

BARRETO, M. L. et al. O que é urgente e necessário para subsidiar as políticas de enfrentamento da pandemia de COVID-19 no Brasil? Revista Brasileira de Epidemiologia, v.23, e200032, 2020.

BLEGER, J. Psicología de la conducta. Buenos Aires: Paidós (Trabalho original publicado em 1963), 2007.

BLEGER, J. Psicohigiene y Psicología Institucional. Buenos Aires: Paidós. 1966.

BLEGER, J. Temas de Psicologia: entrevistas e grupos. 6. ed. São Paulo: Martins Fontes, (Trabalho original publicado em 1980), 1993.

BLEGER, J. Psicoanalisis y dialetica materialista. Buenos Aires: Paidos, 1958.

CAMPS, C. I. C. M.; BARCELOS, T. F.; AIELLO-VAISBERG, T. M. J. Atendimento ser e fazer e escolha profissional: estudo sobre eficácia clínica. Boletim de Psicologia, v.64, v.140, p.21-32, 2014.

CASTELLANO, M. "Só é fracassado quem quer": a subjetividade loser na literatura de autoajuda. Galaxia, São Paulo, n.29, p.167-179, 2015.

CBF SOCIAL. Psicologia no futebol em tempos de pandemia: humanização vs. Intervenção. Confederação Brasileira de Futebol, 2020a. Disponível em:

https://www.cbf.com.br/cbf-tv/webinar-cbf-social-psicologia-no-futebol-em-tempos-depandemia-huma. Acesso em: 30 jun. 2020.

CBF SOCIAL. Serviço Social no Mundo do Futebol em Tempos de Covid-19.

Confederação Brasileira de Futebol, 2020b. Disponível em: https://www.cbf.com.br/acbf/informes/cbf-social/webinar-cbf-social-tem-conversas-e-apresentacoes-sobreservico-social. Acesso em: 30 jun. 2020.

CFP. Resolução no 011/2018. Publicada em 11 de maio de 2018. Regulamenta a prestação de serviços psicológicos realizados por meios de tecnologias da informação e da comunicação e revoga a Resolução CFP N.ํ11/2012. Brasília: Conselho Federal de Psicologia, 2018.

FERNANDES, R, A. Da entrada de serviço ao elevador social: racismo e sofrimento. 2013. 146 f. Dissertação (Mestrado em Psicologia) - Pontifícia Universidade Católica de Campinas, Campinas, 2013. 
FILGUEIRAS, A; STULTS-KOLEHMAINEN, M. The relationship between behavioural and psychosocial factors among brazilians in quarantine due to COVID-19. Lancet, [preprint], 2020. Disponível em: http://dx.doi.org/10.2139/ssrn.3566245. Acesso em: 30 jun. 2020.

GALLO-BELLUZZO, S.R.; CORBETT, E.; AIELLO-VAISBERG, T. M. J. The first experience of clinical practice on psychology students' imaginary. Paidéia, Ribeirão Preto, v.23, n.56, p.389-396, 2013.

GREENBERG, J.; MITCHELL, S. Relações objetais na teoria psicanalítica. Porto Alegre: Artes Médicas, 1994.

HERRMANN, F. O método da psicanálise. São Paulo: EPU, 1979.

LEME, C, G. O futebol como estratégia de ascensão na sociedade de risco: o atleta "sem clube" e sua identidade. 2011. 257 f. Tese (Programa de Pós-graduação em Psicologia Social) - Pontifícia Universidade Católica de São Paulo, São Paulo, 2011.

MANDEL, C, H. O Futebol como porta de saída da pobreza? Analisando indivíduos e organizações. Relatório Final PIBIC - Programa Institucional de Bolsas de Iniciação Científica Ciclo 2015/2016. São Paulo: Fundação Getúlio Vargas, 2016.

MENCARELLI, V. L.; BAPTISTA, A. M.; AIELLO-VAISBERG, T. M. J. Enquadres diferenciados ser e fazer: a princesinha e o veneno da planta da floresta. Estilos da Clínica, São Paulo, v.22, n.2, p.319-338, 2017.

MENDONÇA, R. Como formar jogadoras? O desafio do Brasil na base do futebol feminino. São Paulo: Dibradoras, UOL, 2019. Disponível em: https://dibradoras. blogosfera.uol.com.br/2019/09/18/como-formar-jogadoras-o-desafio-do-brasil-na-basedo-futebol-feminino/. Acesso em: 30 jun. 2020.

PISANI, M. S. "Sou feita de chuva, sol e barro": o futebol de mulheres praticado na cidade de São Paulo. 2018. 245 f. Tese (Programa de Pós-graduação em Antropologia Social) - Universidade de São Paulo, São Paulo, 2018.

POLITZER, G. Crítica dos fundamentos da Psicologia: a Psicologia e a Psicanálise. Piracicaba: Editora Unimep. (Trabalho original publicado em 1928), 2004.

RENAULT, E. A critical theory of social suffering. Critical Horizons, n.11, v.2, p.221241, 2010.

RODRIGUES, M. L. O imaginário de adolescentes sobre o esporte: um estudo psicanalítico. 2016. 134 f. Dissertação (Mestrado em Psicologia) - Pontifícia Universidade Católica de Campinas, Campinas, 2016.

RUBIO, K. O atleta e o mito do herói: o imaginário esportivo contemporâneo. São Paulo: Casa do Psicólogo, 2001.

SILVA, G. C. Narrativas sobre o futebol feminino na imprensa paulista: entre a proibição e a regulamentação (1965-1983). 2015. 135 f. Dissertação (Mestrado em História) - Universidade de São Paulo, São Paulo, 2015. 
SOUZA, J. A construção social da subcidadania: por uma sociologia política da modernidade periférica. Belo Horizonte: Editora UFMG, 2003.

SOUZA J. A invisibilidade da desigualdade brasileira. Belo Horizonte, MG: Editora UFMG, 2006.

SOUZA, J. A ralé brasileira. Belo Horizonte: Editora UFMG, 2009.

VIEIRA, J. J. Paixão nacional e mito social: a participação do negro no Futebol e Ascensão Social. 2001. 337 f. Tese (Programa de Pós-graduação em Sociologia) Instituto Universitário de Pesquisas do Rio de Janeiro, Universidade Candido Mendes, Rio de Janeiro, 2001.

WINNICOTT, D. W. Natureza Humana. Rio de Janeiro: Imago, 1988. 